\title{
Effect of $10 \%$ weight loss on simulated taekwondo match performance: a randomized trial
}

\author{
Leonardo de Sousa Fortes ${ }^{1, *}$, Gustavo César de Vasconcelos' ${ }^{1}$ Bruna Daniella de Vasconcelos Costa', Pedro Pinheiro Paes', \\ Emerson Franchini
}

${ }^{1}$ Graduate Program in Physical Education of Federal University of Pernambuco, Recife, Brazil

${ }^{2}$ Physical Education and Sport School of University of São Paulo, São Paulo, Brazil

The objective of the present study was to analyze the effect of $10 \%$ body mass reduction on simulated taekwondo match performance. Thirty-one male taekwondo athletes were randomly distributed in two groups: weight loss group $(n=15)$ - athletes in this group reduced $5 \%$ body mass per week during two successive weeks, totaling $10 \%$ body mass reduction; control group $(n=16)$ - athletes in this group kept their body mass constant during the 2-week period. Twenty-four hours before and after this period, athletes performed a simulated 3-round taekwondo match $(6 \mathrm{~min})$. Athletes wore body protectors to validate the scores during the match according to the official taekwondo rules.
Match was filmed and actions were categorized using the Game Performance Assessment Instrument. There was a group and time interaction $(P<0.001)$ for body mass, with decrease only for the weight loss group $(P=0.001)$. A group and time interaction was also observed for the taekwondo match performance $(P<0.001)$, with performance increase being found only for the control group $(P=0.01)$. Thus, the $10 \%$ weight loss was not a good strategy to improve taekwondo skills' performance.

Keywords: Martial arts, Body weight, Sports

\section{INTRODUCTION}

Taekwondo is a combat sport characterized by the need of muscle power and agility during successful actions (Santos et al., 2015). Moreover, due to the high speed of actions during the match and the use of feints by the opponent, the taekwondo athlete needs to have a high level of attention and concentration. A typical taekwondo combat is 6 min long (three 2-min rounds interspersed by 1 -min intervals), and the winner is the athlete achieving the highest score during this period or knocking out the adversary (Janiszewska and Przybyłowicz, 2015).

As in many combat sports, taekwondo athletes are also classified according to their body mass in different weight categories (Sant'Anna et al., 2014). A recent study reported a high prevalence of rapid weight loss procedures in taekwondo athletes (da Silva Santos et al., 2016). The rapid weight loss is commonly used by combat sports athletes as a strategy to gain leverage by com- peting against weaker opponents (Franchini et al., 2012).

Competitive performance in combat sports, in general, and taekwondo, specifically, depends on technique (e.g., kicks and punching execution, feints, displacements, stepping), tactics (movement pattern and technique choice according to the opponents' profile), physical abilities, morphological and physiological characteristics (e.g., speed, power, strength, aerobic and anaerobic power and capacity, body composition, limbs length), and psychological (e.g., motivation, focus of attention, anxiety, self-control) (Fortes et al., 2017). Although many studies have analyzed physical and physiological responses to rapid weight loss in combat sports (Abedelmalek et al., 2015; Artioli et al., 2010; Franchini et al., 2012), few studies investigated the technical responses (Artioli et al., 2010), but only in a grappling combat sport (judo). Thus, it is relevant to verify how rapid weight loss would affect taekwondo-specific skills during the match, because this information would help coaches to better understand how the common procedure of weight
${ }^{*}$ Corresponding author: Leonardo de Sousa Fortes (ip https://orcid.org/0000-0002-0778-769X Department of Physical Education and Sports, Federal University of Pernambuco, Avenue Professor Moraes Rego, 1235, Recife/PE - 50670-901, Brazil

Tel: +55-81981144085, Fax: +55-8131323352, E-mail: leodesousafortes@hotmail.com Received: October 11, 2017 / Accepted: December 8, 2017
This is an Open Access article distributed under the terms of the Creative Commons Attribution Non-Commercial License (http://creativecommons.org/licenses/by-nc/4.0/) which permits unrestricted non-commercial use, distribution, and reproduction in any medium, provided the original work is properly cited. 
loss before competition influences the main element of taekwondo (skill execution during the match).

The skill execution index (SEI) is a variable involving metacognitive (anticipation, attention, work memory, and perception) and motor (skill execution) components (Memmert and Harvey, 2008). It is important to emphasize that the taekwondo technique in competitive situation is executed as a result of athlete's experience and tactical knowledge acquired along his/her many years of training (Araújo et al., 2015).

Therefore, the main objective of the present study is to verify the effect of rapid weight loss on the skills execution index of taekwondo athletes submitted to one round of match simulation. Our hypothesis is that this procedure will negatively affect the SEI.

\section{MATERIALS AND METHODS}

\section{Experimental design}

All athletes from experimental group (EG) and control group (CG) were submitted to taekwondo-specific training during 2 weeks (tapering phase). Training description is presented on Table 1. Twenty-four hours before and after the training period athletes fullfilled the Disordered Eating in Sports Scale (Fortes et al., 2016), had their anthropometrical measurements (body mass and skinfold thicknesses) taken and executed a three 2-min round match simulation (Fig. 1). It was decided to adopt the interval of $24 \mathrm{hr}$ between the measurements and the intervention with the premise of maintaining the ecological validity of the study, since in taekwondo there is an interval of 18 to $24 \mathrm{hr}$ between the official weighing and the beginning of the first combat (World Taekwondo Federation [WTF], 2016), although a new weigh-in is allowed up to $2 \mathrm{hr}$ before the start of the first match (WTF, 2016). During the experimental period, athletes were monitored by coaches, physicans, nutritionists, and physioterapists, to assure their health safety. No health problem was detected during the investigation. Strategies for body mass reduction were planned to result in $5 \%$ loss in each week in EG.

\section{Participants}

The sample size analysis was conducted in the G*Power 3.1 software. Power of $0.85, \alpha=0.05$ and effect size (ES) of 0.50 were adopted. Thus, the sample size of 28 subjects was revealed as necessary to conduct the experiment.

Table 1. Microcycle taekwondo training description for athletes in the experimental group (EG) and control group (CG)

\begin{tabular}{|c|c|c|c|c|c|c|}
\hline \multirow{2}{*}{ Microcycle } & \multicolumn{3}{|c|}{ EG } & \multicolumn{3}{|c|}{ CG } \\
\hline & Physical & Technical & Tactical & Physical & Technical & Tactical \\
\hline \multirow[t]{5}{*}{1} & $2 \times R T$ & $2 \times K T T$ & $2 \times \mathrm{DT}$ & $2 \times R T$ & $2 \times K \Pi$ & $2 \times \mathrm{DT}$ \\
\hline & $1 \times \mathrm{ACT}$ & & $2 \times 0 T$ & $1 \times$ ACT & & $2 \times 0 T$ \\
\hline & $1 \times$ CAT & & & $1 \times$ CAT & & \\
\hline & $2 \times A T$ & & & $2 \times A T$ & & \\
\hline & $1 \times \mathrm{APT}$ & & & $1 \times A P T$ & & \\
\hline \multirow[t]{6}{*}{2} & $1 \times R T$ & $1 \times K T T$ & $1 \times \mathrm{DT}$ & $1 \times R T$ & $1 \times K \pi$ & $1 \times \mathrm{DT}$ \\
\hline & $1 \times A C T$ & & $2 \times 0 T$ & $1 \times$ ACT & & $2 \times 0 T$ \\
\hline & $1 \times$ CAT & & & $1 \times$ CAT & & \\
\hline & $2 \times A T$ & & & $2 \times A T$ & & \\
\hline & $1 \times \mathrm{AET}$ & & & $1 \times A E T$ & & \\
\hline & $1 \times \mathrm{APT}$ & & & $1 \times A P T$ & & \\
\hline
\end{tabular}

$R T$, resistance training; $A C T$, aerobic circuit training; CAT, continuous aerobic training; $A T$, agility training; $A P T$, anaerobic power training; $A E T$, anaerobic endurance training; $\mathrm{KTT}$, kick technique training; DT, defensive training; OT, offensive training.

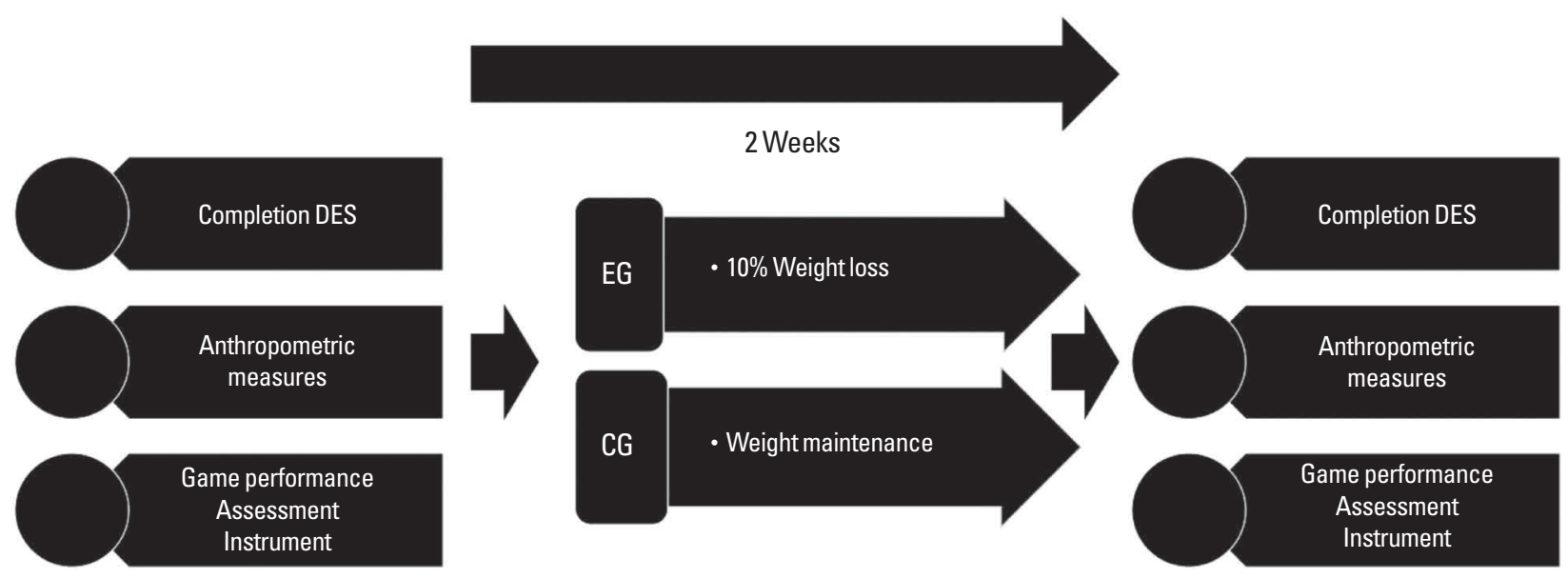

Fig. 1. Experimental design scheme. DES, Disordered Eating in Sports Scale; EG, experimental group; CG, control group. 
To take part in the present study, athletes should: (a) be a taekwondo athlete for at least three years; (b) train systematically for at least $8 \mathrm{hr} / \mathrm{wk}$; (c) be registered in the national championship. Thirty-four male taekwondo athletes (18 to 30 years of age) participants of the Brazilian National Championship were selected to take part in the present study, via nonprobabilistic selection. Athletes were randomly allocated in two groups: experimental (EG, $\mathrm{n}=17$; aged, $23.6 \pm 1.5$ years; training regimen: $10.4 \pm 0.8 \mathrm{hr} / \mathrm{wk}$; body fat: $15.2 \% \pm 4.4 \%$ ); control (CG, $n=17$; aged, $24.1 \pm 1.7$ years; training regimen: $10.5 \pm 0.7 \mathrm{hr} / \mathrm{wk}$; body fat: $16.3 \% \pm 5.2 \%$ ). It should be noted that the study was registered in clinical trials (REQ:4972; UTN: U1111-1195-5011).

Following eligibility screening by the research coordinator, the interactive simple system generated a unique number (1 to 34). In turn, the research coordinator referred to a manual of unique numbers generated by an independent statistician prior to study activation to determine the study intervention allocated to the randomized athlete. The randomization schedule was stratified by site. The allocation flow of the participants can be seen in Fig. 2. It should be noted that, although it is recommended by CONSORT (consolidated standards for reporting of trials) to keep all participants blind, in the present study this procedure was not adopted as it is not possible to have an athlete losing weight without noticing it.

The EG was submitted to 2 weeks of body mass reduction (5\% of body mass reduction per week during 2 weeks, totaling $10 \%$ ), while CG maintained their body mass constant in the same peri- od. Three participants were excluded because they did not answer the questionnaire used to assess weight loss or because they missed more than $10 \%$ of the training session in the 2 -week period. Thus, the final sample was composed by 31 athletes ( $E G=15, C G=16$ ). There were no differences in $\operatorname{SEI}(F[2,29]=2.04, P=0.29, \mathrm{ES}=0.1$, 95\% confidence interval [CI], 0.1-0.3) and body mass $(F[2,29]=$ $2.42, P=0.27, \mathrm{ES}=0.1,95 \% \mathrm{CI}, 0.1-0.4)$ between groups before intervention.

After being completely informed about all procedures, risks and benefits of taking part in the present study, athletes signed an informed consent form. All procedures were approved by the ethics committee of the Federal University of Pernambuco (59783316. 4.0000.5208), Brazil.

\section{Variables measurements \\ Primary outcome}

Game Performance Assessment Instrument (GPAI): Performance in the skills execution was evaluated during three 2-min round match, using the official taekwondo rules (WTF, 2016). All athletes confronted an opponent of the same weight division and similar technical skill. The entire round was filmed using a CANON (SX60 model, Tokyo, Japan) camera. The analysis and actions classification were conducted based on GPAI (Memmert and Harvey, 2008). All kick techniques were considered during the simulated round. Actions resulting in scores were considered appropriated. Body protectors and helmets (Protector Scoring System, KP\&P, Seoul, Korea) were used by the athletes to register scores during combat.

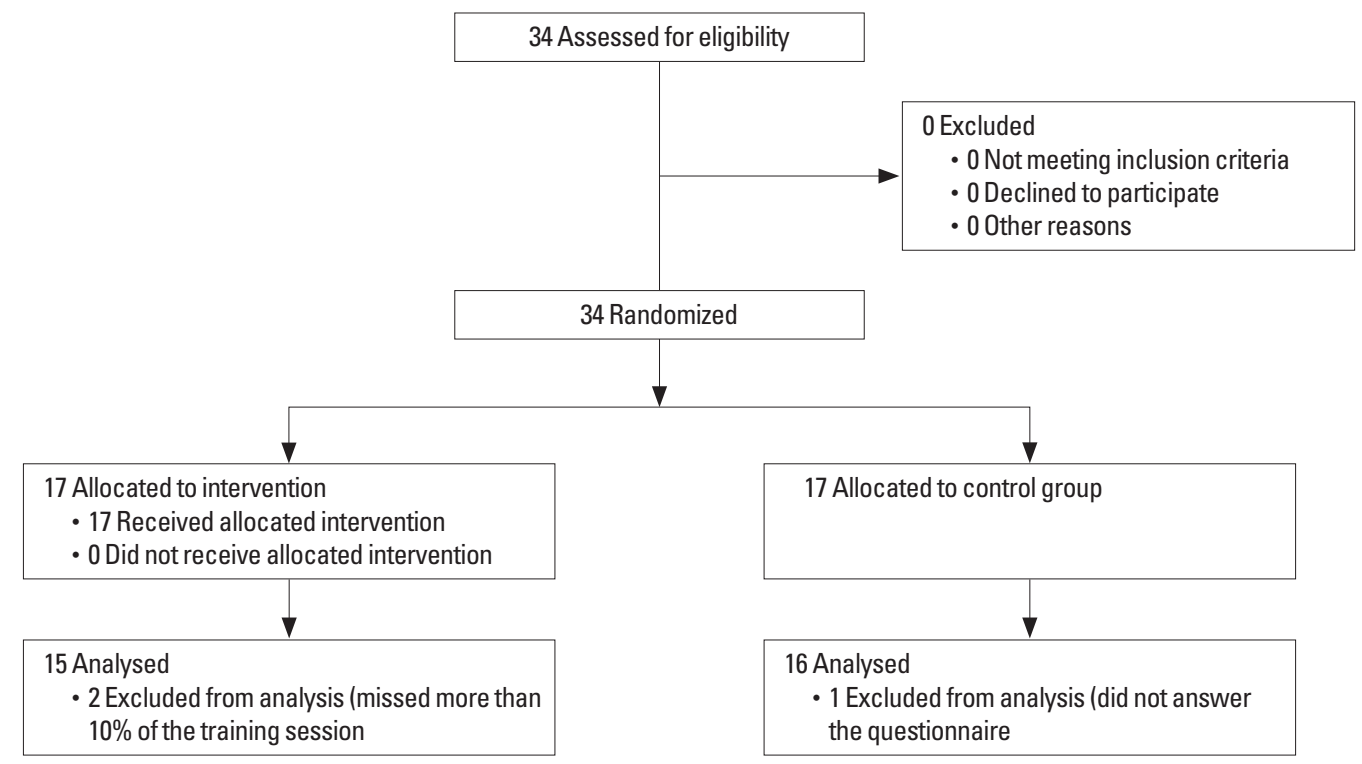

Fig. 2. Allocation of participants (CONSORT [consolidated standards for reporting of trials] flow diagram). 
Therefore, kicks hitting the trunk, kick in the head and kick involving jump hitting the head were considered (WTF, 2016). All appropriate action scores were counted as 1 point. In case of knockout 12 points were registered for the winner (occurred twice).

The SEI was calculated according to the equation below; Aa represents appropriated actions; $\mathrm{Na}$ represents nonapropriated actions, considering the modifications suggested by Memmert and Harvey (2008). Each action was analyzed by two specialists, experienced in taekwondo and classified as appropriated or nonappropriated.

$$
S E I=\frac{A a}{A a+N a}
$$

\section{Secondary outcomes}

Frequency of use of methods to decrease body mass: To verify the frequency of use of methods to decrease body mass the Disordered Eating in Sports Scale (DES; created and validated in Portuguese) was applied (Fortes et al., 2016). This questionnaire is composed by 21 Likert-type questions ( 0 , never; 1 , almost never; 2 , sometimes; 3 , often; 4, always). For the present study, the "food restriction and weight reduction" was used. This subscale is composed by six items ("I practice exercise more than needed thinking about burning calories," "During the training sessions I use extra clothes or rubber suits to lose weight"). The higher the score in this subscale, more the frequency directed to rapid body mass reduction (long-term dietary restriction, appetite suppressant, laxative, sauna and use of warm clothing during physical training). This subscale presented an internal consistency of 0.66 in the original study (Fortes et al., 2016). In the present sample the internal consistency was 0.70 , using the Cronbach alpha.

Anthropometry: Body mass was measured using a portable digital scale (Tanita BC-601, Tanita Corp., São Paulo, Brazil). Triceps, chest and subscapular skinfold thicknesses were measured using a Lange caliper (Lange, Washington DC, USA). To estimate body density, the Jackson and Pollok (1978) equation was used. Body fat was estimated using the Siri (1961) equation.

\section{Statistics}

The Levene test was used to verify homocedasticity. Compound symmetry was verified via Mauchly test with Greenhouse correction when needed. Mean and standard deviation were used as descriptive statistics. Two-way (group and moment) analysis of variance with repeated measurements was used to compare groups in the pre and postintervention moments. The Bonferroni test was used as post hoc. One-way analysis of variance was used to compare basic characteristics between groups. The significance level was set at 5\%. ESs were calculated using Cohen $d$, and classified according to Rhea (2004): $d<0.35=$ trivial, $0.35 \leq d>0.80=$ small, $0.80 \leq d>1.5=$ moderate and, $d \geq 1.5=$ large. IBM SPSS Statistics ver. 21.0 (IBM Co., Armonk, NY, USA) was used to conduct the

Table 2. Body mass, SEI, FRWR subscale score in taekwondo athletes' pre- and postperiod of rapid body mass reduction experimental group (EG) and control group (CG)

\begin{tabular}{|c|c|c|c|c|c|}
\hline Variable & $E G(n=15)$ & $C G(n=16)$ & Effects & $F$ & $P$-value \\
\hline \multicolumn{6}{|c|}{ Body mass (kg) } \\
\hline Preperiod & $73.1 \pm 3.7(65.2-79.4)$ & $73.4 \pm 3.4(64.7-77.0)$ & Group & 44.02 & 0.001 \\
\hline Postperiod & $64.3 \pm 3.9^{*}(61.6-70.5)$ & $72.9 \pm 4.1(66.2-79.1)$ & Time & 38.75 & 0.230 \\
\hline$\Delta \%$ & $-10.3 \pm 1.3(-7.9$ to -11.8$)$ & $-0.5 \pm 0.2(-0.3$ to -1.1$)$ & Interaction & 61.14 & 0.001 \\
\hline$D$ & 1.2 (moderate) & 0.1 (trivial) & & & \\
\hline \multicolumn{6}{|l|}{ SEl (index) } \\
\hline Preperiod & $0.42 \pm 0.1(0.39-0.44)$ & $0.41 \pm 0.1(0.38-0.46)$ & Group & 39.22 & 0.001 \\
\hline Postperiod & $0.43 \pm 0.1(0.37-0.45)$ & $0.49 \pm 0.1^{*}(0.45-0.53)$ & Time & 32.54 & 0.190 \\
\hline$\Delta \%$ & $1.3 \pm 0.4(0.9-2.3)$ & $8.4 \pm 1.6(6.8-9.2)$ & Interaction & 47.70 & 0.001 \\
\hline$D$ & 0.1 (trivial) & 1.1 (moderate) & & & \\
\hline \multicolumn{6}{|c|}{ FRWR subscale } \\
\hline Preperiod & $12.2 \pm 0.7(9.2-15.0)$ & $12.0 \pm 0.8(8.9-14.7)$ & Group & 58.92 & 0.001 \\
\hline Postperiod & $20.1 \pm 1.2^{*}(16.4-23.9)$ & $12.4 \pm 0.9(8.2-15.6)$ & Time & 48.33 & 0.210 \\
\hline$\Delta \%$ & $41.6 \pm 6.1(33.6-44.1)$ & $0.7 \pm 0.3(0.4-1.8)$ & Interaction & 64.59 & 0.001 \\
\hline$D$ & 1.6 (large) & 0.1 (trivial) & & & \\
\hline
\end{tabular}

Values are presented as mean \pm standard deviation (95\% confidence interval).

FRWR, food restriction and weight reduction; SEl, skill execution index; $\Delta \%$, percentage of change

${ }^{*} P<0.05$ vs. pre. 
Table 3. Skill execution index (SEI) in taekwondo athletes' first, second, and third rounds according to experimental group (EG) and control group (CG)

\begin{tabular}{|c|c|c|c|c|c|}
\hline SEl & $E G(n=15)$ & $C G(n=16)$ & Effects & $F$ & $P$-value \\
\hline \multicolumn{6}{|l|}{ Pre } \\
\hline First round & $0.39 \pm 0.2(0.37-0.48)$ & $0.41 \pm 0.1(0.36-0.43)$ & Group & 3.39 & 0.31 \\
\hline Second round & $0.42 \pm 0.2(0.36-0.46)$ & $0.38 \pm 0.2(0.33-0.44)$ & Time & 4.01 & 0.33 \\
\hline Third round & $0.41 \pm 0.1(0.34-0.45)$ & $0.42 \pm 0.1(0.40-0.49)$ & Interaction & 4.76 & 0.46 \\
\hline$D$ & 0.1 (trivial) & 0.1 (trivial) & & & \\
\hline \multicolumn{6}{|l|}{ Post } \\
\hline First round & $0.45 \pm 0.1(0.36-0.48)$ & $0.44 \pm 0.1(0.40-0.49)$ & Group & 36.23 & 0.01 \\
\hline Second round & $0.40 \pm 0.2^{\#}(0.32-0.45)$ & $0.51 \pm 0.2^{*}(0.42-0.55)$ & Time & 38.05 & 0.03 \\
\hline Third round & $0.42 \pm 0.1(0.35-0.48)$ & $0.48 \pm 0.2^{*}(0.44-0.58)$ & Interaction & 41.98 & 0.02 \\
\hline$D$ & 0.6 (small) & 1.0 (moderate) & & & \\
\hline
\end{tabular}

Values are presented as mean \pm standard deviation (95\% confidence interval).

$\mathrm{Cl}$, confidence interval.

${ }^{*} P<0.05$ vs. EG. ${ }^{*} P<0.05$ vs. first round.

statistical tests.

\section{RESULTS}

No significant differences were found between groups for age ( $P=0.25)$, body fat percentage $(P=0.21)$, frequency of use of methods to rapid body mass reduction $(P=0.27)$ and performance in the SEI $(P=0.29)$.

Table 2 presents the pre and post results for each group. There was a group and moment interaction $(P<0.001)$ for body mass, with reduction only for the EG $(P=0.001 ; d=1.2$, moderate; $95 \%$ CI, 0.9-1.5). A significant group and moment interaction $(P<$ 0.001) was also observed for the SEI, with improvement only for the CG ( $P=0.01 ; d=1.1$, moderate, 95\% CI, 0.7-1.4).

For the food restriction and weight reduction subscale, there was a group and moment interaction $(P<0.001)$, with score increase only for the $\mathrm{EG}(P=0.01 ; d=1.6$, large; $95 \% \mathrm{CI}, 1.1-1.8)$.

The findings revealed a total of $53 \pm 8(95 \% \mathrm{CI}, 49-58)$ and $51 \pm 7$ (95\% CI, 48-55) actions in the pre- and postexperiment for the CG. Similarly, the results indicated $52 \pm 7$ (95\% CI, $47-$ $54)$ and $50 \pm 8$ (95\% CI, 47-56) actions in the pre- and postexperiment in EG. It should be noted that $23 \pm 5$ (95\% CI, 20-29) and $24 \pm 5$ (95\% CI, 20-28) of these actions were considered appropriate for $\mathrm{CG}$ and $\mathrm{EG}$ in the pre-experiment, respectively. It is noteworthy that in the post-experiment, $22 \pm 5$ (95\% CI, 19-28) and $26 \pm 4$ (95\% CI, 22-29) of the actions were considered appropriate for $C G$ and $E G$, respectively.

Table 3 presents the SEI of the first, second and third rounds for each group according to moment (pre and post). There was a group and moment interaction $(P<0.01)$ for SEI only postexperiment, with improvement for the CG in the second $(P=0.02 ; d=0.8$, moderate; 95\% CI, 0.4-1.0) and third rounds ( $P=0.01 ; d=1.0$, moderate; $95 \% \mathrm{CI}, 0.7-1.5)$ and impairment for the EG in the second round ( $P=0.03 ; d=0.6$, small; $95 \% \mathrm{CI}, 0.4-1.2$ ).

\section{DISCUSSION}

The present investigation analyzed the effect of $10 \%$ body mass reduction on SEI in taekwondo athletes during three 2-min round match. The results demonstrated that this reduction did not affect SEI, but the same variable was increased in the CG, confirming partially the initial hypothesis established.

Thus, it can be suggested that the adoption of rapid body mass reduction methods (use of plastic/rubber suits, sauna, laxatives ,and appetite inhibition pills) can result in the absence of performance gains, which was found in athletes decreasing their body mass, confirming the findings from Davids et al. (2013) and Romeas et al. (2016). In this sense, 2 weeks of specific taekwondo training in the tapering phase (overcompensation effect) could potentiate the SEI, as the findings revealed in the CG. Conversely, it appears that $10 \%$ of body mass reduction in 2 weeks can attenuate SEI, causing a balance between performance gain from specific taekwondo training in the tapering phase and loss of performance due to rapid reduction weight, leading to the maintenance of SEI, as the results demonstrated for EG.

One possible explanation for this finding is that the rapid body mass reduction could reduce the blood flow to the telencephalon and the nerve impulse conduction velocity (Pallarés et al., 2016), resulting in decrease of the metacognitive performance (Kinrade et al., 2015). Therefore, considering that the reduction in the tele- 
cephalon blood flow results in decreased oxygenation for superior brain areas (Soares et al., 2017), it is possible to assume that rapid body mass reduction can attenuate attention and anticipation abilities, factors considered essential for skill execution performance (Araújo et al., 2015). It is also worth noting that the rapid body mass reduction leads to dehydration (Pallarés et al., 2016), which may be directly related to the reduction of nerve impulse conduction velocity. In this sense, the rapid body mass reduction, even if indirectly, can attenuate the response time between information processing and motor execution, which, in a way, can also explain the results found for EG after 2-week period.

Additionally, it is important to emphasize that combat sports where the weight category divisions are used, and more specifically in taekwondo, athletes decrease their body mass several times during the competitive season (Santos et al., 2015). Concerning the food restriction and weight reduction subscale, the findings of the present study revealed an increase in scores in the EG and no change in the $\mathrm{CG}$ after the 2-week period. This was accompanied by a decrease in body mass by the EG and maintenance for the CG. Thus, considering that dehydration is a common strategy to achieve the desired body mass (Brito et al., 2012; da Silva Santos et al., 2016), taekwondo athletes probably will present the negative consequences of such strategy including hormonal imbalance, increased risk of injury, decreased mineral bone content (Hunter et al., 2014) and the development of disordered eating (Chapman and Woodman, 2016). Caution should be taken when considering our results, as the main limitations of the present study were the absence of a multicompartimental method to assess athletes' body composition and the absence of their hydration status.

In conclusion, the results of the present study indicated that although the rapid body mass reduction did not negatively affect the SEI in taekwondo athletes, it did not allow them to improve performance as verified in the CG.

\section{CONFLICT OF INTEREST}

No potential conflict of interest relevant to this article was reported.

\section{ACKNOWLEDGMENTS}

The authors gratefully acknowledge the contributions of participants (taekwondo athletes) and Luiz Marques in their indispensable role as research assistants in this study. The experiments comply with the current laws of the Brazil.

\section{REFERENCES}

Abedelmalek S, Chtourou H, Souissi N, Tabka Z. Caloric restriction effect on proinflammatory cytokines, growth hormone, and steroid hormone concentrations during exercise in Judokas. Oxid Med Cell Longev 2015; 2015:809492.

Araújo D, Davids K, Diniz A, Rocha L, Santos JC, Dias G, Fernandes O. Ecological dynamics of continuous and categorical decision-making: the regatta start in sailing. Eur J Sport Sci 2015;15:195-202.

Artioli GG, Iglesias RT, Franchini E, Gualano B, Kashiwagura DB, Solis MY, Benatti FB, Fuchs M, Lancha Junior AH. Rapid weight loss followed by recovery time does not affect judo-related performance. J Sports Sci 2010;28:21-32.

Brito CJ, Roas A FC, Brito ISS, Marins J CB, Córdova C, Franchini E. Methods of body mass reduction by combat sport athletes. Int J Sport Nutr Exerc Metab 2012;22:89-97.

Chapman J, Woodman T. Disordered eating in male athletes: a meta-analysis. J Sports Sci 2016;34:101-109.

da Silva Santos JF, Takito MY, Artioli GG, Franchini E. Weight loss practices in Taekwondo athletes of different competitive levels. J Exerc Rehabil 2016;12:202-208.

Davids K, Araújo D, Correia V, Vilar L. How small-sided and conditioned games enhance acquisition of movement and decision-making skills. Exerc Sport Sci Rev 2013;41:154-161.

Fortes LS, Almeida SS, Ferreira MEC. Psychometric analysis of Disordered Eating in Sports Scale (DES). Paidéia (Ribeirão Preto) 2016;26:171-180.

Fortes LS, Lira HA, Ferreira ME. Effect of rapid weight loss on decisionmaking performance in judo athletes. J Phys Educ 2017;28:e21-28.

Franchini E, Brito CJ, Artioli GG. Weight loss in combat sports: physiological, psychological and performance effects. J Int Soc Sports Nutr 2012; 9:52.

Hunter GR, Plaisance EP, Fisher G. Weight loss and bone mineral density. Curr Opin Endocrinol Diabetes Obes 2014;21:358-362.

Jackson AS, Pollock ML. Generalized equations for predicting body density of men. Br J Nutr 1978;40:497-504.

Janiszewska K, Przybyłowicz KE. Pre-competition weight loss among Polish taekwondo competitors - occurrence, methods and health consequences. Arch Budo 2015;11:41-45.

Kinrade NP, Jackson RC, Ashford KJ. Reinvestment, task complexity and decision making under pressure in basketball. Psychol Sport Exerc 2015;20:11-19.

Memmert D, Harvey S. The Game Performance Assessment Instrument (GPAI): some concerns and solutions for further development. J Teach Phys Educ 2008;27:220-240.

Pallarés JG, Martínez-Abellán A, López-Gullón JM, Morán-Navarro R, De 
la Cruz-Sánchez E, Mora-Rodríguez R. Muscle contraction velocity, strength and power output changes following different degrees of hypohydration in competitive Olympic combat sports. J Int Soc Sports Nutr 2016;13:10.

Rhea MR. Determining the magnitude of treatment effects in strength training research through the use of the effect size. J Strength Cond Res 2004;18:918-920.

Romeas T, Guldner B, Faubert J. 3D-multiple object tracking training task improves passing decision-making accuracy in soccer players. Psychol Sport Exerc 2016;22:1-9.

Sant'Anna J, Diefenthaeler F, Dal Pupo J, Detanico D, Guglielmo LG, Santos SG. Anaerobic evaluation of Taekwondo athletes. Int SportMed J 2014;15:492-499.
Santos JF, Valenzuela TH, Franchini E. Can different conditioning activities and rest intervals affect the acute performance of taekwondo turning kick? J Strength Cond Res 2015;29:1640-1647.

Siri WE. The gross composition of the body. In: Tobias CA, Lawrence JH, editors. Advances in biological and medical physics. New York: Academic Press, 1961. p. 239-280.

Soares AH, Oliveira TP, Cavalcante BR, Farah BQ, Lima AH, Cucato GG, Cardoso-Júnior CG, Ritti-Dias RM. Effects of active recovery on autonomic and haemodynamic responses after aerobic exercise. Clin Physiol Funct Imaging 2017;37:62-67.

World Taekwondo Federation. International taekwondo rules [Internet]. Seoul: World Taekwondo; 2016 [cited 2016 Jul 10]. Available from: www.worldtaekwondofederation.net. 